\title{
Fluorescence properties in different solvents and synthesis of axially substituted silicon phthalocyanine bearing bis-4-tritylphenoxy units
}

https://doi.org/10.1515/hc-2020-0113

Received January 21, 2020; accepted August 05, 2020.

Abstract: In this present study, a new axially bis-4tritylphenoxy substituted silicon phthalocyanine compound was synthesized and characterized using infrared, mass, electronic absorption and nuclear magnetic resonance spectroscopy. Fluorescence and absorption spectra studies of the disubstituted silicon phthalocyanine complex were conducted on the chloroform, dimethyl formamide, dimethyl sulfoxide and tetrahydrofuran solutions. The findings of the fluorescence studies demonstrated that the compound has fluorescence spectra in the different solvents. The effects of the substitution with axially bis-4-tritylphenoxy functionalized groups on these parameters were also compared with the previously synthesized axially disubstituted silicon phthalocyanines. These results proved that the compound has different fluorescence properties in the different solvents.

Keywords: synthesis, characterization, fluorescence, silicon phthalocyanine, aggregation, solubility

\section{Introduction}

Phthalocyanines have potential applications in different areas such as photovoltaic cells [1-2], chemical sensor [3], semiconductors [4], electrochromic displaying systems [5], non-linear optics [6], laser dyes [7], optical storage devices [8], catalysts [9], photosensitizers [10] and liquid crystals [11]. Additionally, axially functionalized phthalocyanines were studied in different areas such as enzyme inhibition, bacterial diseases, antioxidant purposes, enzyme inhibition, electrochemistry, organic light-emitting devices (OLED), biomarkers and

\footnotetext{
*Corresponding author: Mehmet Salih Ağırtaş, Department of Chemistry, Faculty of Science, Van Yuzuncu Yıl University, 65080, Van, Turkey, E-mail: salihagirtas@hotmail.com
}

photodynamic therapy (PDT) [12-16]. In these compounds, the central metal ions have a very decisive effect upon the photophysical properties of metallophthalocyanine compounds. Particularly, closed-shell and diamagnetic ions, such as zinc(II), gallium(III), and silicon(IV) form metallophthalocyanine compounds having both long lifetimes and high triplet yields, and are good candidates for photocatalytic applications, such as photodynamic therapy [17-18]. There are two reasons for the research into silicon phthalocyanines. One of them is high resolution due to axial binding. Axially substituted phthalocyanine compounds increase the solubility of phthalocyanines in solvents and facilitate the investigation of their physical and chemical properties. The other reason is that it prevents aggregation in the solvent medium due to the axial bond [19]. Porphyrins are known to be used as a PDT agent for some types of cancer. However, instead of this agent, phthalocyanine compounds with superior properties have begun to be used. Phthalocyanines have ideal properties such as high singlet oxygen, chemical stability, low dark toxicity and absorption in the red region [20]. In the literature, our group has already synthesized metallo phthalocyanines bearing tritylphenoxy substituents, and these substituents showed dye sensitized solar cell (DCCS) properties [21]. These studies demonstrated that the substituent group could also be used as a solar cell. It is expected that the functionality of the tritylphenoxy group will increase by axially bonding to silicon phthalocyanine. When it shows fluorescence properties, it may show the potential to be used as an effective sensor agent in PDT applications. The factors expected to be effective in axially substituted phthalocyanines are low aggregation tendency, higher solubility and more dominant fluorescence lifetimes [22-23].

The aim of this study is to synthesize of axially tritylphenoxy disubstituted silicon phthalocyanine compounds, and to study the fluorescence and aggregation properties of the compound in different solvents. 


\section{Results and Discussion}

\section{Synthesis and Characterization}

The synthetic route and structures of the bis - (4-tritylphenoxy) phthalocyaninato silicon (IV) (3) is as shown in Scheme 1. The compound (3) was obtained by a reaction between silicon phthalocyanine dichloride 1 and 4-tritylphenol $\mathbf{2}$ in the presence of dry $\mathrm{K}_{2} \mathrm{CO}_{3}$ in dry toluene under a nitrogen atmosphere for $30 \mathrm{~h}$ at refluxed temperature. The complex was purified by extraction and purity was checked by TLC. Whether sufficient purification has been achieved or not was decided with TLC controls. The new phthalocyanine compound was characterized using mass, FT-IR, ${ }^{1} \mathrm{H}$ NMR, ${ }^{13} \mathrm{C}$ NMR, and UV-vis spectroscopy methods.

The FT-IR spectrum helps to characterize functional groups. The most obvious indicator for compound $\mathbf{3}$ is the complete disappearance of the $\mathrm{OH}$ vibration peaks observed in the starting material. As expected, characteristic aromatic peaks $(\mathrm{Ar}-\mathrm{H})$ were observed at $3055 \mathrm{~cm}^{-1}$. The $\mathrm{C}=\mathrm{C}$ vibration peaks that should be present in the structure are observed at 1593 and $1508 \mathrm{~cm}^{-1}$ as expected. Compound $3 \mathrm{Si}-\mathrm{O}-\mathrm{C}$ stretch peak was observed at $1080 \mathrm{~cm}^{-1}$ as expected in accordance with the data in the literature [24].

The mass spectrum of the newly synthesized compound 3 was obtained by analysis with ESI mass spectrometer. The mass spectral principle is based on matching the measured correct mass and the isotopic form of a sample. It is decided whether the structure is confirmed by the mass agreement of the isotope measured by the calculated mass of the compound. Mass spectra studies were carried out for the axially disubstituted silicon phthalocyanine and the mass spectra peaks of the compound were observed at $1211.42[\mathrm{M}+\mathrm{H}]^{+}$. The finding verifies the structure of the synthesized compound.

The structure of axially disubstituted silicon phthalocyanine 3 was also confirmed by ${ }^{1} \mathrm{H}$ NMR for the through aromatic ring protons in its respective regions except for small shifts. In the ${ }^{1} \mathrm{H}$ NMR spectrum of compound 3 in DMSO- $\mathrm{d}_{6}$, aromatic protons appeared at range 7.826.66(Ar-H) ppm. In the ${ }^{13} \mathrm{C}$ NMR spectrum of compound 3 in DMSO- $\mathrm{d}_{6}$, aromatic protons were observed at 147.28, 131.99, 130.90, 128.00, 126.25, $114.81 \mathrm{ppm}$. The ${ }^{1} \mathrm{H}$ NMR and ${ }^{13} \mathrm{C}$ NMR spectra of the compound were shown in Figures 1 and 2.

Investigation of phthalocyanine compounds in terms of aggregation provides information about the interaction of the structure with the solvent along with the characteristic information about the structure. These properties

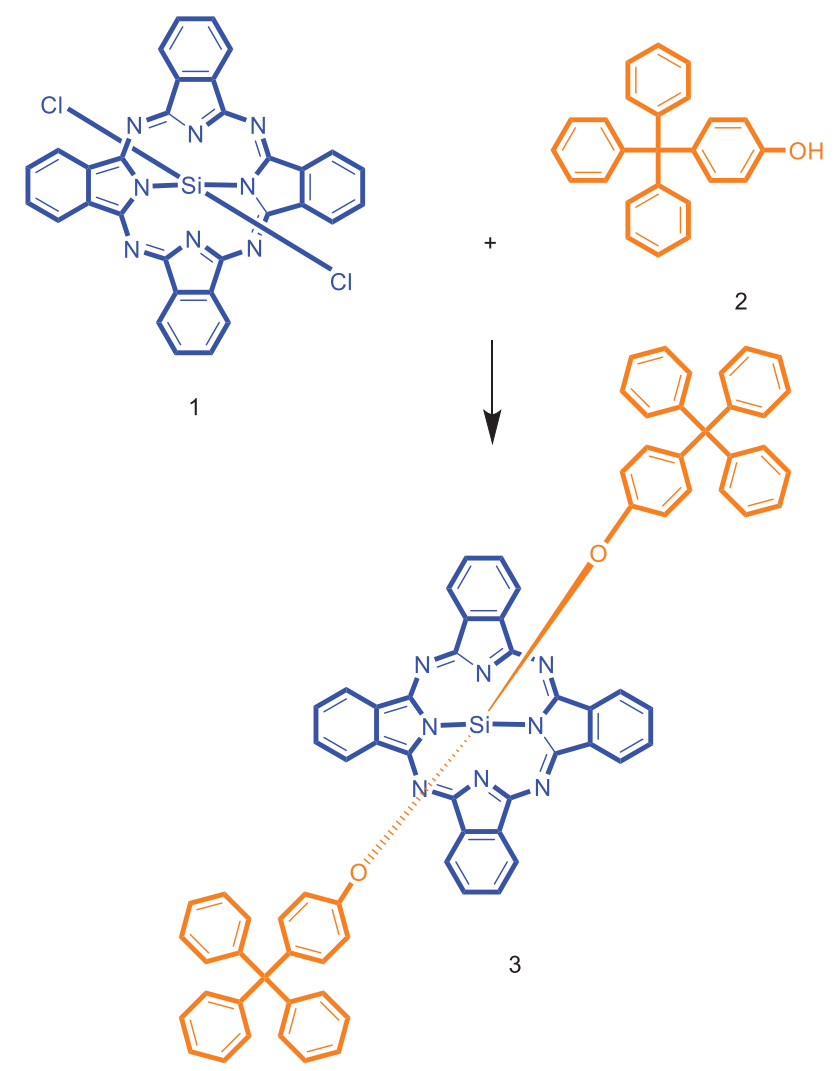

Scheme 1 Synthesis of axially bis-4-tritylphenoxy substituted silicon phthalocyanine 3

are dominated due to the $\pi-\pi^{\star}$ transitions within the heteroaromatic 18- $\pi$ electron system [25-26]. In particular, axial phthalocyanine complexes are expected to be non-aggregates. Therefore, it attracts the attention of researchers. Monomer behavior with good solubility is desirable for applications. The phthalocyanine compound has the characteristic $Q$ band at $672 \mathrm{~nm}$ and the $B$ band at $354 \mathrm{~nm}$. In this study, the aggregation behavior of the external phthalocyanine compound was investigated at different concentrations in tetrahydrofuran (THF) as shown in Figure 3. The concentration-dependent aggregation showed that the $\mathrm{Q}$ and $\mathrm{B}$ bands are not affected, and also the Lambert-Beer law was obeyed for different concentrations in the THF. This result indicated that the compound acts as a monomer in THF solution. In addition to the above methods, the UV absorption titration studies of the compound in different solutions showed the same pattern (Figure 4). These electronic data verified that the compound could be used for many applications in the near future.

The fluorescence compounds are used as disease diagnostics, bio-labeling, enzyme substrate, environmental indicator, cell organelle labeling, organic radiation-emitting diodes and sensor agents; and they have a wide range 


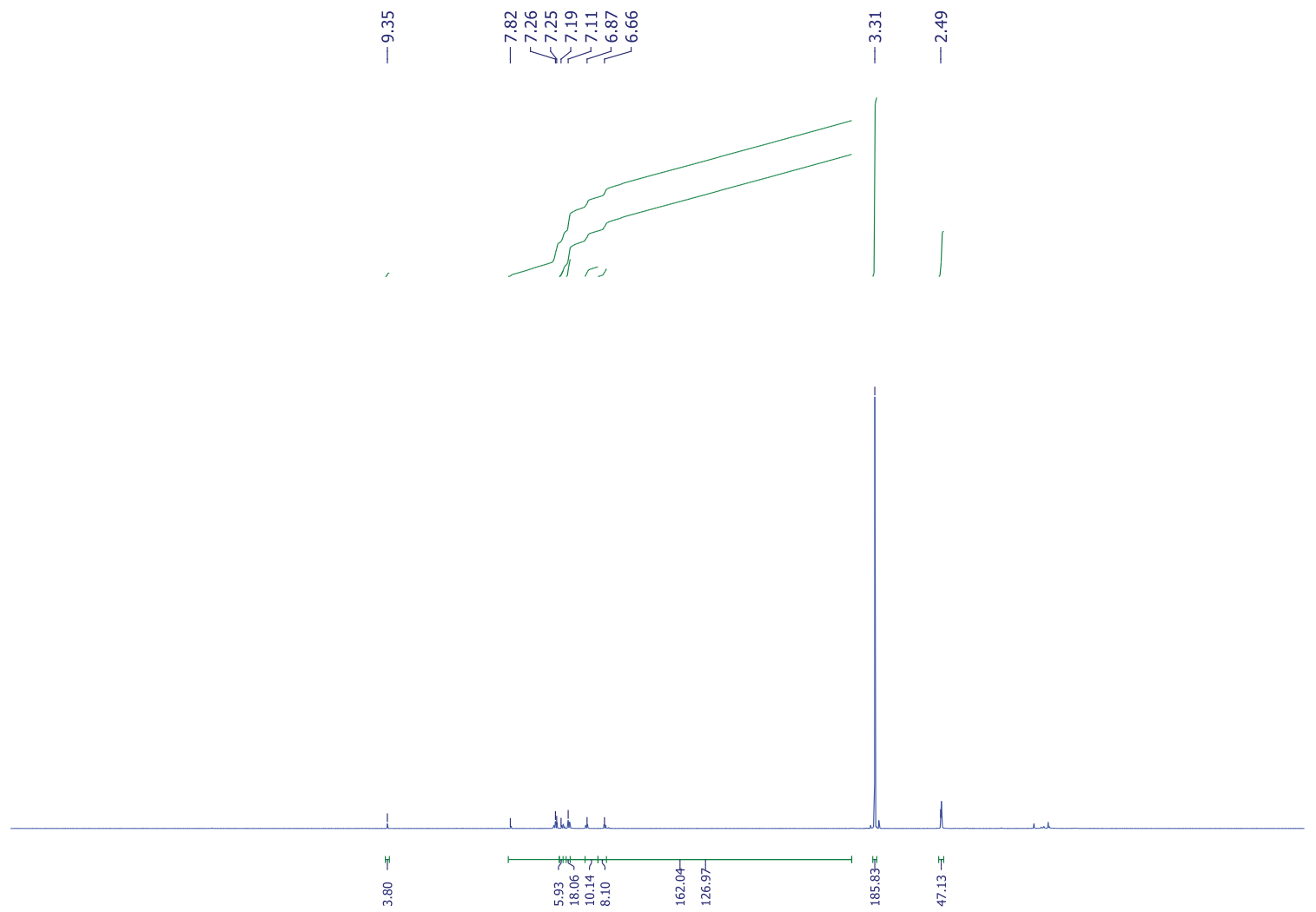

Figure $1{ }^{1} \mathrm{H}-\mathrm{NMR}$ spectrum of axially disubstituted silicon phthalocyanine 3

$$
\text { 总 }
$$

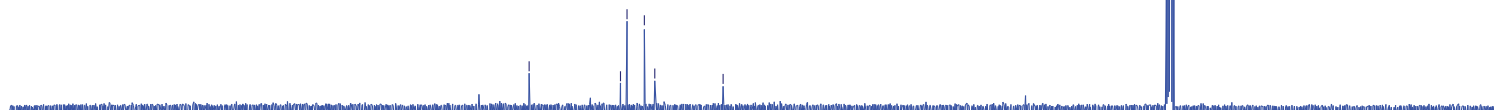

Figure $2{ }^{13}$ C-NMR spectrum of axially bis-4-tritylphenoxy substituted silicon phthalocyanine 3 


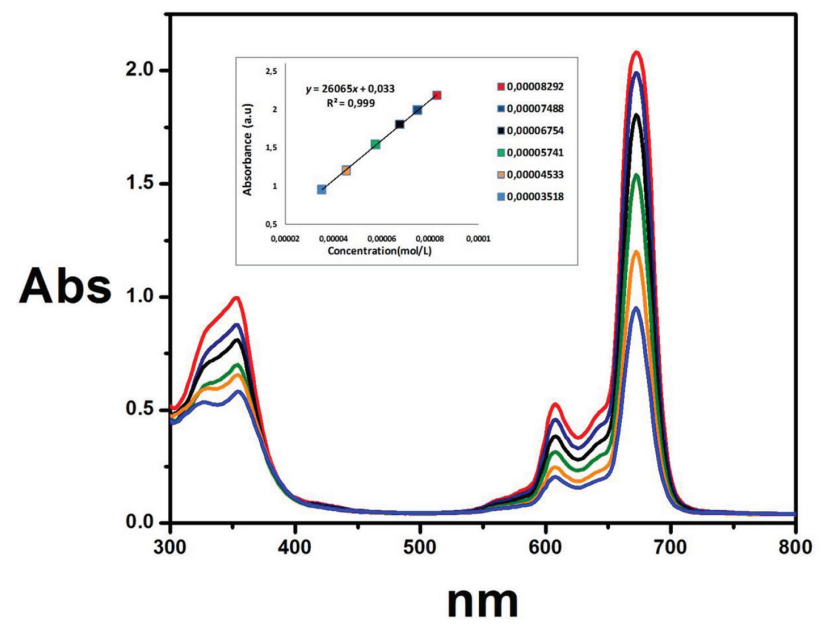

Figure 3 UV-Vis spectrum of axially disubstituted silicon phthalocyanine 3 in THF at different concentrations

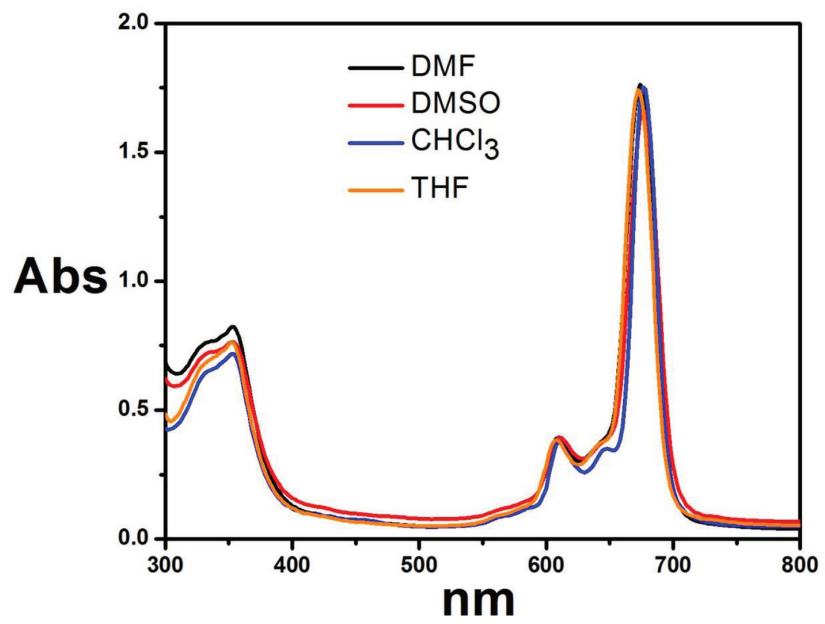

Figure 4 UV-Vis spectrum of axially disubstituted silicon phthalocyanine 3 at different solvents

of common uses in chemistry, biology and physics. The nature of substituents on axial positions can strongly influence essential parameters of a phthalocyanine, such as its solubility in organic solvents, aggregation behavior, electronic absorption, photophysical and photochemical properties. Due to the solubility of axially substituted silicone phthalocyanine compound $\mathbf{3}$ in many different solvents, different solvents such as chloroform $\left(\mathrm{CHCl}_{3}\right)$, dimethyl formamide (DMF), dimethyl sulfoxide (DMSO) and tetrahydrofuran were used for fluorescence absorption, excitation and emission spectra of this compound. The observed spectra are shown in Figure 5-8. Stokes shifts obtained in the studied solvent media are consistent with the literature data given for phthalocyanines. The excitation spectra are similar to the absorption spectra and form mirror images of the fluorescence spectra for the studied silicon phthalocyanine complex. This indicates

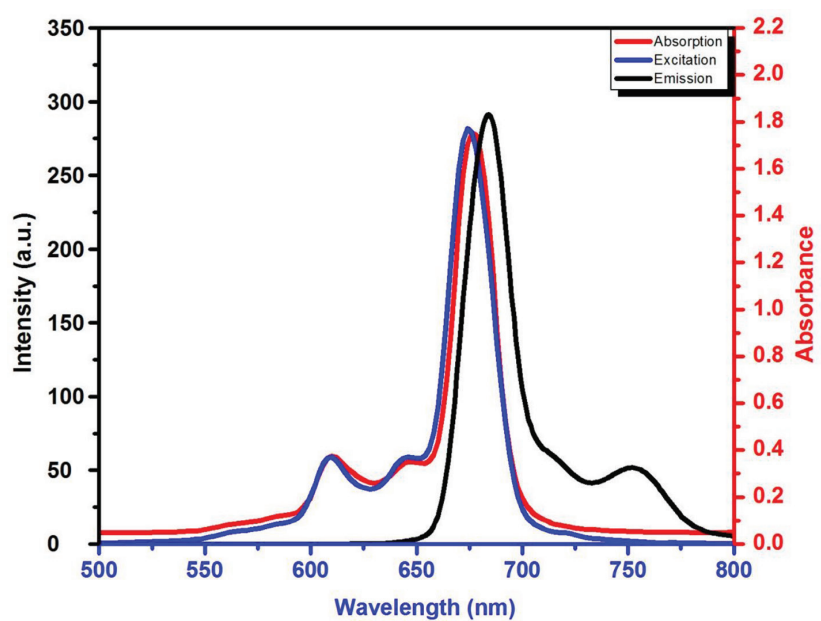

Figure 5 Emission, excitation, and absorption spectra of axially bis4-tritylphenoxy substituted silicon phthalocyanine 3 in $\mathrm{CHCl}_{3}$

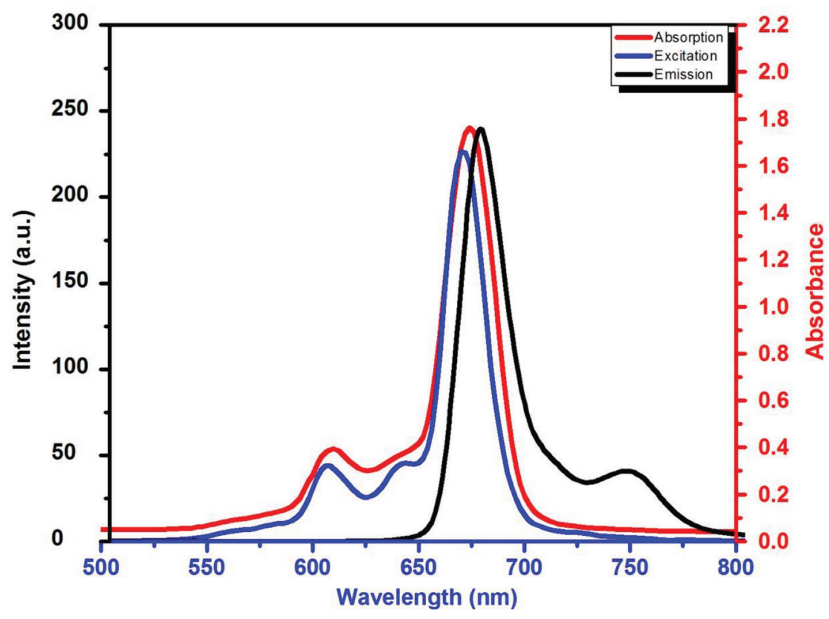

Figure 6 Emission, excitation, and absorption spectra of axially bis4-tritylphenoxy substituted silicon phthalocyanine 3 in DMF

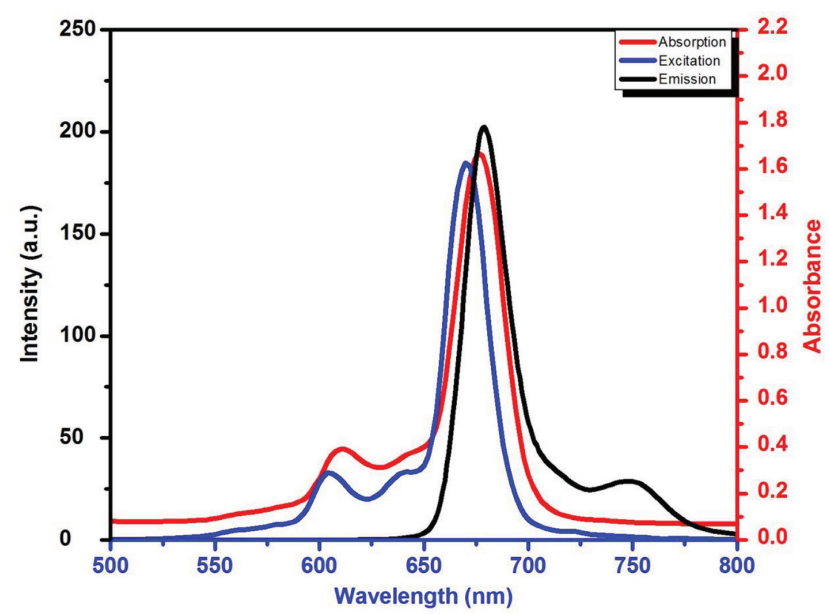

Figure 7 Emission, excitation, and absorption spectra of axially bis4-tritylphenoxy substituted silicon phthalocyanine 3 in DMSO 


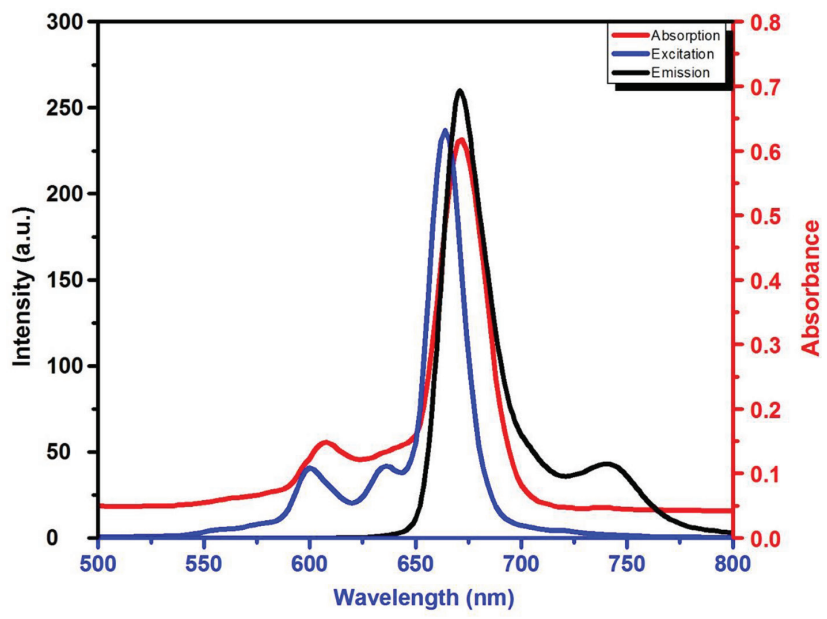

Figure 8 Emission, excitation, and absorption spectra of axially bis4-tritylphenoxy substituted silicon phthalocyanine 3 in THF

Table 1 Spectral parameters of the complex 3 in different solvents

\begin{tabular}{lccccl}
\hline Sample & $\begin{array}{c}\text { Q band } \\
\lambda \max (\mathrm{nm})\end{array}$ & $\log \varepsilon$ & $\begin{array}{c}\text { Excitation } \\
\lambda_{\mathrm{Ex}}(\mathrm{nm})\end{array}$ & $\begin{array}{c}\text { Emission } \\
\lambda_{\mathrm{Em}}(\mathrm{nm})\end{array}$ & $\begin{array}{l}\text { Stokes shift } \\
\Delta_{\text {Stokes }}(\mathrm{nm})\end{array}$ \\
\hline 3 & 676 & 5.24 & 674 & 681 & 7 (in $\left.\mathrm{CHCl}_{3}\right)$ \\
3 & 674 & 5.25 & 666 & 672 & 6 (in DMF) \\
3 & 676 & 5.22 & 670 & 675 & 5 (in DMSO) \\
3 & 672 & 5.31 & 664 & 667 & 3 (in THF) \\
\hline
\end{tabular}

that the compound does not show any degradation during excitation in the different solvents used. The fluorescence Stokes-shift values of the axially dispersed silicon phthalocyanine vary depending on the solvent effect. This value was $7 \mathrm{~nm}$ for chloroform, $6 \mathrm{~nm}$ for DMF, $5 \mathrm{~nm}$ for DMSO and $3 \mathrm{~nm}$ for THF. Stokes shift values with fluorescence emission and excitation maxima are shown in Table 1. Fluorescence excitation and emission values of axial silicon phthalocyanine were found to be in accordance with the values in the literature [27-28]. The fluorescence property of the compound in different solvents has the potential to be used in different areas.

\section{Conclusions}

In this study, a new disubstitued silicon phthalocyanine compound was synthesized for the first time. This novel compound was characterized by spectroscopic data such as FT-IR, Mass, UV-Vis, ${ }^{1} \mathrm{H}$ NMR and ${ }^{13} \mathrm{C}$ NMR. The phthalocyanine compound was observed to have monomer behavior in the different measured ranges of concentration in THF. At the same time, the fluorescence of the compound was examined in different solvents and showed fluorescence in all of the studied solvents. This property allows different solvents to be used in applications. This behavior of the compound can be interpreted that as a potentially sensitizing agent it may be used for photodynamic therapy. Furthermore, the absence of aggregation of the compound in the solvent medium is advantageous for applications.

\section{Experimental}

\section{General}

Potassium carbonate $\left(\mathrm{K}_{2} \mathrm{CO}_{3}\right)$, 4-tritylphenol, tetrahydrofuran, chloroform, silicon phthalocyanine dichloride, toluene, were commercially provided from companies such as Sigma, Aldrich and Merck. The purification of solvents was performed according to procedures found in literature [29]. A digital electrothermal apparatus was used for the melting point. The structures were analyzed by Hitachi U-2900 Spectrophotometer, Thermo Scientific FT-IR spectrophotometer, Agilent $400 \mathrm{MHz}$ spectrometer, a Shımadzu RF-6000 spectrofluorophotometer and LC-MS TOF electrospray ionization technique.

\section{Bis - (4-tritylphenoxy) phthalocyaninato silicon (IV) (3)}

$\mathrm{SiPcCl}_{2}$ (75mg, 0.12mmol), 4-tritylphenol (81mg, 0.24mmol) and $\mathrm{K}_{2} \mathrm{CO}_{3}(0.055 \mathrm{~g}, 0.39 \mathrm{mmol})$ were mixed with dry toluene $(10 \mathrm{~mL})$ and refluxed for $30 \mathrm{~h}$. After the product mixture reached room temperature, the organic fraction was separated by extraction (chloroform: water). After removing the solvent. Yield: $33 \mathrm{mg}(45 \%)$, m.p. $>300^{\circ} \mathrm{C}$. IR (ATR), v/ $\mathrm{cm}^{-1}: 3055$ (Ar-H), 1593, 1508, 1440, 1361, 1261, 1163, 1122, 1080, 827, 750, 700. 'H NMR (400MHz, DMSO$\left.\mathrm{d}_{6}\right),(\delta): 7.82,7.26,7.19,7.11,6.88,6.66,3.31,2.49 .{ }^{13} \mathrm{C}$ NMR (400MHz, DMSO-d $\mathrm{d}_{6}$, (8):147.28, 131.99, 130.90, 128.00, 126.25, 114.81, 40.61, 40.40, 40.19, 39.98, 39.77, 39.56, 39.35. MS (ESI), (m/z): Calculated: 1210.41; Found: 1211.42 $[\mathrm{M}+\mathrm{H}]^{+}$. UV-Vis (THF, $\left.1 \times 10^{-5} \mathrm{M}\right): \lambda \max / \mathrm{nm}(\log \varepsilon): 672$ (5.29), 608 (4.66), 354 (4.94).

Acknowledgments: The author would like to thank Van Yuzuncu Yll University Scientific Research Projects Office for the project support numbered FAP-2019-8345.

Conflict of interest: The author states no conflict of interest. 


\section{References}

[1] Xu J, Yang W, Chen R. The photovoltaic performance of highly asymmetric phthalocyanine-sensitized brookite-based solar cells. Optik (Stuttg). 2020;200:163413.

[2] Wu S, Liu Q, Zheng Y, Li R, Peng T. An efficient copper phthalocyanine additive of perovskite precursor for improving the photovoltaic performance of planar perovskite solar cells. J Power Sources. 2017;359:303-10.

[3] Ağırtaş MS, Altındal A, Salih B, Saydam S, Bekaroğlu Ö. Synthesis, characterization, and electrochemical and electrical properties of novel mono and ball-type metallophthalocyanines with four 9,9-bis(4-hydroxyphenyl)fluorene. Dalton Trans. 2011;40:3315-24.

[4] Dong Z, Kong X, Wu Y, Zhang J, Chen Y. High-sensitive room- temperature NO2 sensor based on a soluble n-type phthalocyanine semiconductor. Inorg Chem Commun. 2017;77:18-22.

[5] Solis C, Baigorria E, Milanesio ME, Morales G, Durantini EN, Otero L, et al. Electrochemical polymerization of EDOT modified Phthalocyanines and their applications as electrochromic materials with green coloration, and strong absorption in the Near-IR. Electrochim Acta. 2016;213:594-605.

[6] AğırtaşMS, KarataşC, GümüşS. Synthesis, Aggregation Behavior, and Electronic Properties of some Metallophthalocyanines with 2-Isopropyl-5-methylphenoxy Substituents. Z Anorg Allg Chem. 2015;641:1334-9.

[7] Lin KC, Doane T, Wang L, Li P, Pejic S, Kenney ME, et al. Laser spectroscopic assessment of a phthalocyanine-sensitized solar cell as a function of dye loading. Sol Energy Mater Sol Cells. 2014;126:155-62.

[8] Sindelo A, Kobayashi N, Kimura M, Nyokong T. Physicochemical and photodynamic antimicrobial chemotherapy activity of morpholine-substituted phthalocyanines: effect of point of substitution and central metal. J Photochem Photobiol Chem. 2019;374:58-67.

[9] Farahmand S, Ghiaci M, Razavizadeh JS. Copper phthalocyanine as an efficient and reusable heterogeneous catalyst for direct hydroxylation of benzene to phenol under mild conditions. Inorg Chim Acta. 2019;484:174-9.

[10] Lipatovaa IM, Yusovaa AA, Lukyanets EA. Supramolecular complexation of the cationic derivative of Zn (II)phthalocyanine and sodium alginate in mixed aqueous solutions. J Photochem Photobiol Chem. 2018;364:588-94.

[11] Sukhikh AS, Klyamer DD, Parkhomenko RG, Krasnov PO, Basova TV. Effect of fluorosubstitution on the structure of single crystals, thin films and spectral properties of palladium phthalocyanines. Dyes Pigm. 2018;149:348-55.

[12] Miretti M, Clementi R, Tempesti TC, Baumgartner MT. Photodynamic inactivation of multiresistant bacteria (KPC) using zinc(II)phthalocyanines. Bioorg Med Chem Lett. 2017;27(18):4341-4.

[13] Ağırtaş MS, Güngördü Solğun D, Özdemir S, İzgi MS. Synthesis of Tetra 3,4-dimethoxyphenethoxy Peripheral Substituted Metallophthalocyanines and Investigation of Some Properties. ChemistrySelect. 2018;3:3523-8.

[14] Ma YY, Hua XC, Zhai TS, Li YH, Fung MK. Doped copper phthalocyanine via an aqueous solution process for highperformance organic light-emitting diodes. Org Electron. 2019;68:236-41.

[15] Silva N, Castro-Castillo C, Oyarzún MP, Ramírez S, Zagal JH. Modulation of the electrocatalytic activity of Fe phthalocyanine to carbon nanotubes: electrochemistry of l-cysteine and l-cystine. Electrochim Acta. 2019;308:295-306.

[16] Attia MS, Ali K, El-Kemary M, Darwish WM. Phthalocyaninedoped polystyrene fluorescent nanocomposite as a highly selective biosensor for quantitative determination of cancer antigen 125. Talanta. 2019;201:185-93.

[17] Shen XM, Jiang XJ, Huang CC, Zhang HH, Jian-Dong Huang JD. Highly photostable silicon(IV) phthalocyanines containing adamantane moieties: synthesis, structure, and properties. Tetrahedron. 2010;66:9041-8.

[18] Skupin-Mrugalska P, Szczolko W, Gierlich P, Konopka K, Goslinski T, Mielcarek J, et al. Physicochemical properties of liposomeincorporated 2-(morpholin-4-yl)ethoxy phthalocyanines and their photodynamic activity against oral cancer cells. J Photochem Photobiol Chem. 2018;353:445-57.

[19] Ağırtaş MS. Highly soluble phthalocyanines with hexadeca tertbutyl substituents. Dyes Pigm. 2008;79:247-51.

[20] Bandera Y, Burdette MK, Shetzline JA, Jenkins R, Creager SE, Foulger SH. Synthesis of water soluble axially disubstituted silicon (IV) phthalocyanines with alkyne \& azide functionality. Dyes Pigm. 2016;125:72-9.

[21] Güngördü Solğun D, Horoz S, Ağırtaş MS. Synthesis of novel tetra (4-tritylphenoxy) substituted metallophthalocyanines and investigation of their aggregation, photovoltaic, solar cell properties. Inorg Nano-Metal Chem. 2018;48(10):508-14.

[22] Barker CA, Findlay KS, Bettington S, Batsanov AS, Perepichka IF, Bryce MR, et al. Synthesis of new axially-disubstituted silicon-phthalocyanine derivatives: optical and structural characterization. Tetrahedron. 2006;62:9433-9.

[23] Zimcik P, Malkova A, Hruba L, Miletin M, Novakova V. Bulky 2,6-diphenylphenylsulfanyl substituents efficiently inhibit aggregation in phthalocyanines and tetrapyrazinoporphyrazines and control their photophysical and electrochemical properties. Dyes Pigm. 2017;136:715-23.

[24] Ömeroğlu İ, Kaya EN, Göksel M, Kussovski V, Mantareva V, Durmus M. Axially substituted silicon(IV) phthalocyanine and its quaternized derivative as photosensitizers towards tumor cells and bacterial pathogens. Bioorg Med Chem. 2017;25:5415-22. 
[25] Ağırtas MS. Synthesis and characterization of novel symmetrical phthalocyanines substituted with four benzo [d] [1,3] dioxol-5ylmethoxy groups. Inorg Chim Acta. 2007;360:2499-502.

[26] Hu L, Zhang H, Gao A, Hou A. Functional modification of cellulose fabrics with phthalocyanine derivatives and the UV light-induced antibacterial performance. Carbohydr Polym. 2018;201:382-6.

[27] Sen P, Nyokong T. A novel axially palladium(II)-Schiff base complex substituted silicon(IV) phthalocyanine: Synthesis, characterization, photophysicochemical properties and photodynamic antimicrobial chemotherapy activity against Staphylococcus aureus. Polyhedron. 2019;173:114135.

[28] Sen P, Sindelo A, Mafukidze DM, Nyokong T. Synthesis and photophysicochemical properties of novel axially disubstituted silicon (IV) phthalocyanines and their photodynamic antimicrobial chemotherapy (PACT) activity against Staphylococcus aureus. Synth Met. 2019;258:116203.

[29] Armarego WL, Chai CL. Purification of laboratory Chemicals. 7th ed. Oxford: Butterwordh-Heinemann; 2013. 